\title{
Preablation three-dimensional ultrasonography can predict therapeutic effect and local tumor progression after radiofrequency ablation for hepatocellular carcinoma
}

\author{
Yukako Matsuki ${ }^{\text {a }}$, Tomomitsu Matono ${ }^{a}$, Masahiko Koda ${ }^{\text {b, }}$, Kenichi Miyoshi ${ }^{\text {a }}$, \\ Takaaki Sugihara $^{a}$, Jun-ichi Okano ${ }^{\text {a }}$, Hajime Isomoto ${ }^{a}$ \\ ${ }^{a}$ Division of Medicine and Clinical Science, Department of Multidisciplinary Internal Medicine, School of Medicine, Tottori University Faculty of Medicine, Yonago 683- \\ 8504, Japan \\ ${ }^{\mathrm{b}}$ Department of Internal Medicine, Hino Hospital, Tottori 683-4504, Japan
}

\section{A R T I C L E I N F O}

\section{Keywords:}

Three-dimensional ultrasonography

Radiofrequency ablation

Hepatocellular carcinoma

Ablative margin

\begin{abstract}
A B S T R A C T
Purpose: To assess the agreement between ablative margin (AM) predicted by preablation three-dimensional ultrasonography (3D-US) and AM measured on postablation computed tomography (CT)/magnetic resonance (MR) images.

Methods: Sixty patients with 73 hepatocellular carcinoma nodules were enrolled. 3D-US data were collected immediately after puncture by the electrode before ablation. The maximum distance from the electrode to the edge of the tumor in the plane perpendicular to the electrode (C-plane) was defined as "a" and the diameter of the ablation zone as " $b$ ". We classified predicted AM into " $0.5 \mathrm{~b}-\mathrm{a}$ " $\geq 0 \mathrm{~mm}$ as $\mathrm{AM}(+)$ or $<0 \mathrm{~mm}$ as $\mathrm{AM}(-)$, and " $0.5 \mathrm{~b}-\mathrm{a}$ " $\geq 3 \mathrm{~mm}$ or $<3 \mathrm{~mm}$.

Results: Forty-eight nodules (66 \%) were visualized in the C-plane. There was an agreement between the predicted and measured AMs for 39 (81 \%) of the 48 nodules. Local tumor progression was observed in $3(7 \%)$ of 43 nodules with predicted $\mathrm{AM}(+)$ and in $2(40 \%)$ of 5 nodules with predicted $\mathrm{AM}(-)$ but was not observed in any of 21 nodules with predicted $A M \geq 3 \mathrm{~mm}$. The local tumor progression rate was significantly lower for nodules with predicted $\mathrm{AM}(+)$ compared with predicted $\mathrm{AM}(-)(\mathrm{p}=0.03)$, and for nodules with predicted $\mathrm{AM} \geq 3 \mathrm{~mm}$ compared with predicted AM $<3 \mathrm{~mm}(\mathrm{p}=0.04)$. Local progression was detected in $2(4.7 \%)$ of 42 nodules with a sufficient AM $(\geq 0 \mathrm{~mm})$ on postablation CT/MR images and in $5(83.3 \%)$ of 6 nodules with an insufficient AM $(<0 \mathrm{~mm})$; the difference in progression rate was significant $(\mathrm{p}=0.0008)$.

Conclusion: 3D-US allows prediction of the AM before radiofrequency ablation.
\end{abstract}

\section{Introduction}

Hepatocellular carcinoma (HCC) is the fourth leading cause of death from cancer worldwide [1]. Several guidelines [2,3] have been developed for the treatment of HCC. Surgical resection, local therapies such as radiofrequency ablation (RFA), microwave ablation (MWA), and embolization, chemotherapy, and radiation are selected based on the size and number of tumors and liver function [4]. Tumor ablation procedures (RFA and MWA) are the main locoregional therapies, for which the overall survival rates have been reported to be the same as those of surgical resection [5]. Therefore, RFA is now widely used to treat HCC [6], and the position of puncture by the RFA electrode into the HCC tumor is an important factor affecting the therapeutic effect. Local tumor progression rates after RFA in the range of $1.6 \%-26 \%$ has been reported [7-12]. Independent predictors of local tumor progression after RFA for HCC are reported to be tumor size and an insufficient ablative margin (AM) [11,13-16]. Pathological studies after hepatic resection have demonstrated the presence of microsatellite nodules around the original

Abbreviations: 2D-US, two-dimensional ultrasonography; 3D-US, three-dimensional ultrasonography; AM, ablative margin; CT, computed tomography; Gd-EOB-

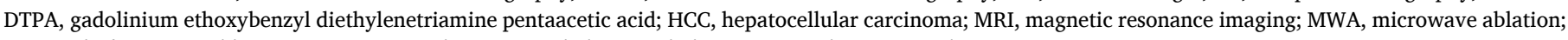
RFA, radiofrequency ablation; TACE, transcatheter arterial chemoembolization; US, ultrasonography.

* Corresponding author.

E-mail address: masakodamasakoda@gmail.com (M. Koda). 
tumor, although these nodules cannot be detected by any imaging modality [17]. Therefore, it is necessary to obtain an ablation zone of normal tissue around the original tumor. A sufficient AM, which is defined as a $5 \mathrm{~mm}$ or larger ablative margin around the entire tumor, has been reported to contribute to a lower local tumor progression rate and longer patient survival [13].

Contrast-enhanced computed tomography (CT), magnetic resonance imaging (MRI), and ultrasonography (US) are widely used to evaluate the AM after RFA. Contrast-enhanced US has also been utilized for evaluation of the AM immediately after RFA $[18,10]$.

The AM is usually assessed by a section-by-section comparison of enhanced CT/MR images obtained pre-RFA and post-RFA [13]. Several more precise methods for assessing AM have been studied, including pre-CT and post-CT fusion imaging [19,20], coronal reformatted CT imaging [21], and MRI enhanced with gadolinium ethoxybenzyl diethylenetriamine pentaacetic acid (Gd-EOB-DTPA) administered prior to RFA [22,23]. Furthermore, AM has been assessed on fusion images obtained by preablation 3D-US and postablation 3D contrast-enhanced US with the aid of a magnetic navigation system [24]. However, these methods need to be performed at a certain interval after RFA and so there is a delay when the AM is judged to be insufficient. It would be of benefit to patients if the effect of treatment could be predicted at the site of puncture by the RFA electrode before ablation. Therefore, we have devised a novel method for prediction of the AM before ablation whereby the positional relationship between the tumor and needle can be evaluated by 3D-US and the AM can be predicted using a virtual ablation volume that is set according to the position of the needle immediately after puncture of the RFA electrode. The aims of this study were to assess the agreement between the AM measured by enhanced $\mathrm{CT} / \mathrm{MRI}$ after RFA and the AM predicted by the proposed method before RFA and to compare the cumulative local tumor progression rates according to predicted AM with those according to measured AM.

\section{Materials and methods}

\subsection{Patients}

This study was approved by the ethics review board of our university hospital (approval numbers: 1511A075, 17A125). Written informed consent was obtained from all patients. RFA was applied according to the treatment algorithm for HCC in the Clinical Practice Guideline for Hepatocellular Carcinoma 2013 published by the Japan Society of Hepatology [4]. The following inclusion criteria were applied: a maximum of 3 HCC nodules; each nodule $\leq 3 \mathrm{~cm}$ in maximal diameter; Child-Pugh grade A or B; all HCC nodules visible by US; all HCC nodules accessible via the percutaneous route; percent activity of prothrombin time $>40 \%$; and platelet count $>40,000$ cells $/ \mathrm{mm}^{3}$. All patients met these criteria. Seventy-six HCC nodules were diagnosed by CT/MRI from July 2014 to February 2016. Forty-seven nodules were diagnosed by enhanced CT and 30 by enhanced MRI using Gd-EOB-DTPA. One patient was performed both dynamic CT and MRI. On a dynamic enhanced CT/MRI study, hyperenhancement in the arterial phase with washout in the portal phase or low-intensity in the hepatobiliary phase of MRI with Gd-EOB-DTPA was diagnosed as HCC. Two nodules that were not evaluated by CT/MRI after RFA and 1 nodule without follow-up examination after RFA were excluded. Seventy-three HCC nodules in 60 patients were included and assessed by 3D-US immediately after RFA electrode puncture.

\subsection{RFA procedures}

RFA was performed under US guidance using a real-time convex scanner with $3.75 \mathrm{MHz}$ probes (Aplio 500: Toshiba, Tokyo, Japan) and a biopsy guide device. RFA was performed as described previously [25]. The RF3000 system with expandable electrodes (Boston Scientific Corp., Natick, MA) was used to treat 35 nodules (48\%), the Cool-tip system
(Radionics, Burlington, MA) for 16 nodules (22\%), and the VIVA RF system (STARmed, Gyeonggi-do, South Korea) for 22 nodules (30 \%).

The RF3000 system consists of a 16- or 17-gauge expandable RFA device with 10 solid retractable curved electrodes with array diameters of 2-3 cm (LeVeen Needle Electrode; Boston Scientific Corporation). The electrode was positioned in the tumor and the array was then expanded in 3-5 steps. The diameter of the array at each step was 10, 15, 20,25 , and $30 \mathrm{~mm}$. In the first step, hooks were deployed at an array diameter of $10 \mathrm{~mm}$. The RF power was initially applied at $30 \mathrm{~W}$ and then increased at $10 \mathrm{~W} / \mathrm{min}$ until it impeded out (i.e., the rapid rise in impedance stopped the current flow and ablation). The second step was started at the RF power level reached in the first step, and the RF power was increased at $10 \mathrm{~W} / \mathrm{min}$ until it impeded out. This cycle was repeated at each step until full extension of the array. Additional ablation was applied at $70 \%$ of maximum power until either it impeded out or $15 \mathrm{~min}$ had elapsed.

When the Cool-tip or VIVA RF system was used, the RF power was increased from $30 \mathrm{~W}$ at $10 \mathrm{~W} / \mathrm{min}$ for a $2-\mathrm{cm}$ exposed tip and by $20 \mathrm{~W} /$ min from $40 \mathrm{~W}$ for a $3-\mathrm{cm}$ exposed tip until maximum power was reached or it impeded out. After the device had impeded out three times, the power was decreased by $20 \mathrm{~W}$ for a 3-cm exposed tip or by $10 \mathrm{~W}$ for a 2-cm exposed tip, and ablation was continued for $12 \mathrm{~min}$.

\subsection{Preablation $3 D$-US data acquisition and assessment of AM predicted by $3 D-U S$}

The 3D-US data were collected using a PVT-675 MV transducer immediately after puncture by the RFA electrode before ablation. The time taken to acquire the 3D-US data was approximately $10 \mathrm{~s}$. These data were analyzed using the following method. The long axis of the puncture needle was taken as the Z-axis, the XZ-plane as the A-plane, and the YZ-plane as the B-plane. The $\mathrm{XY}$-plane, which is a plane perpendicular to the puncture needle, was taken as the C-plane. The positional relationship between the tumor and the puncture needle in the C-plane was analyzed (Fig. 1). We defined the maximum distance from the RFA electrode to the tumor edge as "a" mm and the diameter of the ablation zone, which is determined by the size of the RFA electrode, as " $\mathrm{b}$ " $\mathrm{mm}$. The predicted AM is the minimum distance of " $0.5 \mathrm{~b}-\mathrm{a}$ ". If this distance was $\geq 0 \mathrm{~mm}$, it was defined as predicted $\mathrm{AM}(+)$; if it was $<0 \mathrm{~mm}$, it was defined as predicted $\mathrm{AM}(-)$ (Fig. 2). We also classified predicted AM into " $0.5 \mathrm{~b}-\mathrm{a}$ " $\geq 3 \mathrm{~mm}$ and " $0.5 \mathrm{~b}-\mathrm{a}$ " $<3 \mathrm{~mm}$ assuming that $\geq 3 \mathrm{~mm}$ corresponded to complete ablation. The time taken to perform all procedures was approximately 5-7 $\mathrm{min}$.

\subsection{Assessment of AM measured by postablation CT/MRI}

CT/MRI was performed within a month of RFA for the posttreatment evaluation. Four nodules were evaluated by dynamic enhanced CT, 40 by MRI enhanced with Gd-EOB-DTPA $(0.1 \mathrm{~mL} / \mathrm{kg}$ body weight, administered before RFA) within $7 \mathrm{~h}$ after RFA as in our previous report [23], and four were evaluated by non-enhanced MRI within $7 \mathrm{~h}$ after RFA [26]. AM on postablation MRI was classified as follows. AM(+) was defined as a low-intensity area with a continuous high-intensity rim where the low-intensity area does not extend beyond the high-intensity rim and a continuous rim is seen around the nodule on multidirectional MR images; $\operatorname{AM}(0)$,was defined as a low-intensity area with a discontinuous high-intensity rim where the low-intensity area does not extend beyond the rim and the rim is partially discontinuous; and $\mathrm{AM}(-)$ was defined as a low-intensity area that extends beyond the rim with protrusion of the tumor. In this study, we further classified the measured $\mathrm{AM}$ as sufficient $[\mathrm{AM}(+)$ and $\mathrm{AM}(0)]$ or insufficient $[\mathrm{AM}(-)]$ (Fig. 3).

On dynamic CT, the AM was defined as the area of ablated hepatic parenchyma surrounding the treated HCC nodules. Hyperenhancement in the arterial phase with washout in the portal phase around the ablated areas was judged as residual tumor. No residual tumor was assessed as having a sufficient AM and when residual tumor was observed it was 
$\mathbf{a}$

b

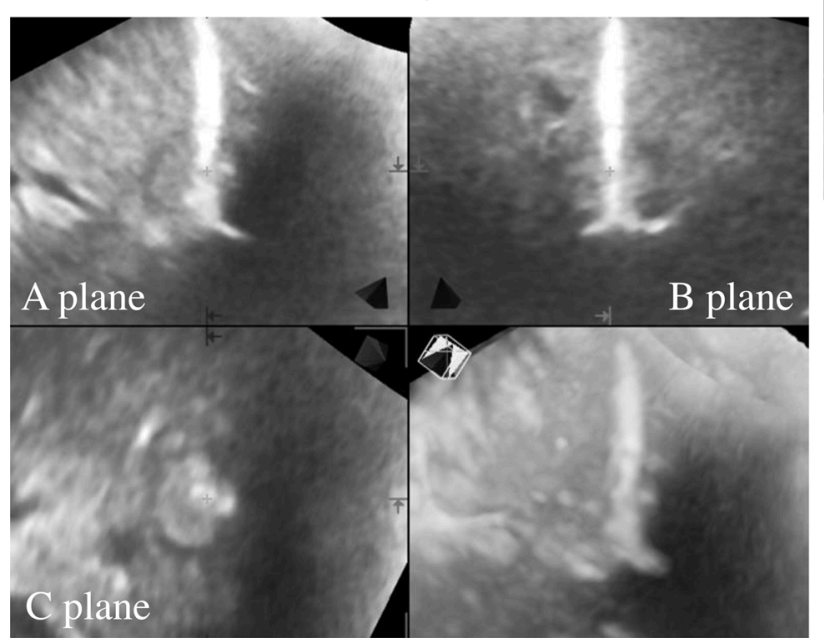

C

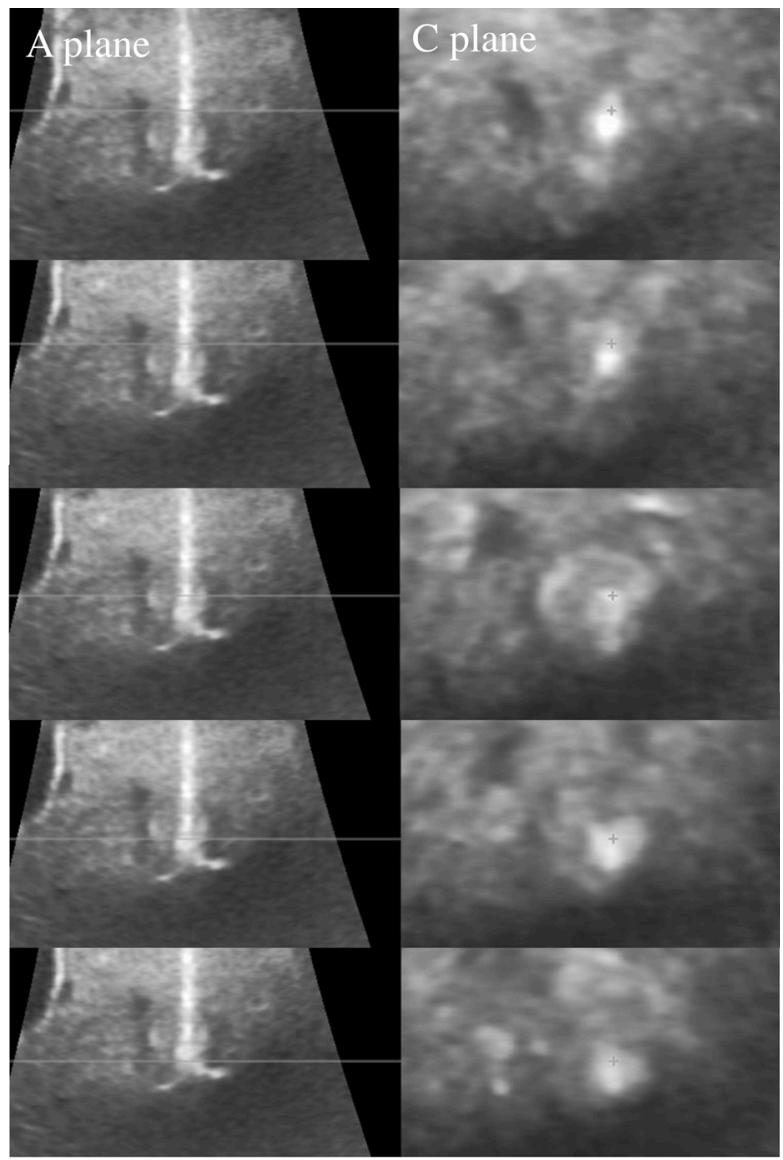

Fig. 1. Analysis of three-dimensional ultrasound volume data.

(a) The Z axis was taken along the electrode needle, the XZ-plane was defined as the A-plane, the YZ-plane as the B-plane, and the XY-plane vertical to the electrode needle as the C-plane. (b) The positional relationship between the HCC nodule and the RFA electrode was visualized in each plane. (c) The positional relationship between the HCC nodule and RFA electrode in the C-plane is shown at each depth in the A-plane. HCC, hepatocellular carcinoma; RFA, radiofrequency ablation.

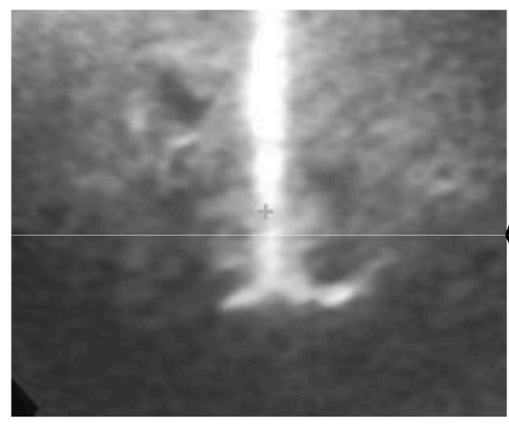

$\mathrm{A} / \mathrm{B}$ plane

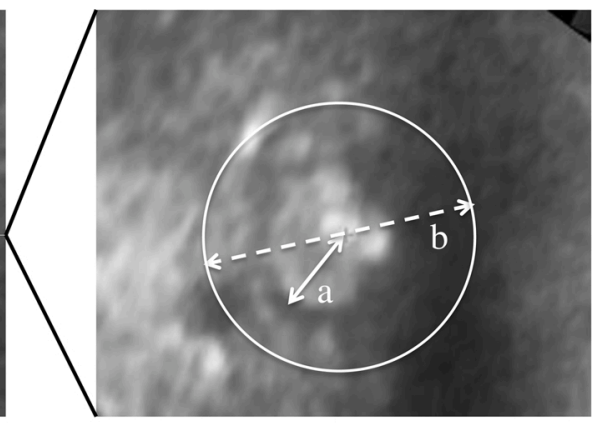

C plane
Fig. 2. Analysis of volume data obtained by three-dimensional ultrasound immediately after puncture of the RFA electrode before ablation.

The C-plane was analyzed at the center of the tumor in A-plane or B-plane. "a" was defined as the longest distance from the electrode to the tumor edge and "b" as the predicted ablation diameter (depending on the size of the electrode). The predicted AM was calculated as " $0.5 \mathrm{~b}-\mathrm{a}$ ". When the AM was $\geq 0 \mathrm{~mm}$, it was defined as predicted $\mathrm{AM}(+)$. If this distance was $<0 \mathrm{~mm}$, it was defined as predicted $\mathrm{AM}(-)$. Furthermore, nodules were classified according to whether predicted AM was $\geq 3 \mathrm{~mm}$ or $<3 \mathrm{~mm}$. AM, ablative margin.

\section{Predicted ablative margin $(\mathrm{AM})=0.5 \mathrm{~b}-\mathrm{a}$ \\ $>0$ predicted $\mathrm{AM}(+)$ \\ $\leq 0$ predicted AM(-)}

assessed to have an insufficient AM.

To evaluate the cumulative local tumor progression rates according to the predicted AM determined on preablation 3D-US and actual AM measured by postablation CT/MRI, all patients were followed up every 3 months with measurement of serum alpha-fetoprotein (normal $<12 \mathrm{ng}$ / $\mathrm{mL}$ ) and des-gamma-carboxy prothrombin (normal $<40 \mathrm{mAU} / \mathrm{mL}$ ) levels, as well as enhanced CT or enhanced MRI. Local tumor progression was defined as a recurrent tumor within or adjacent to the treated 

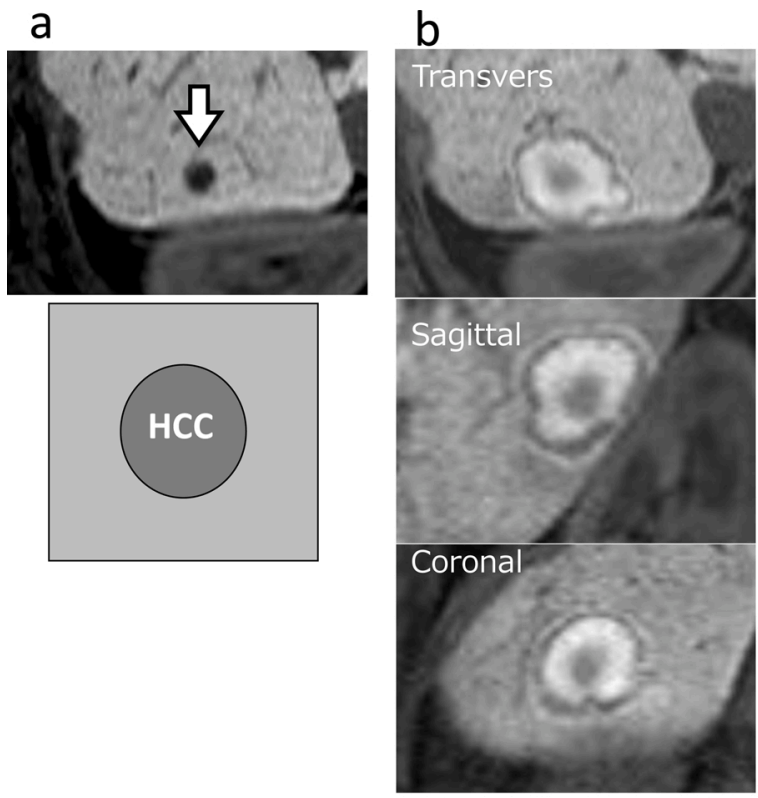

C
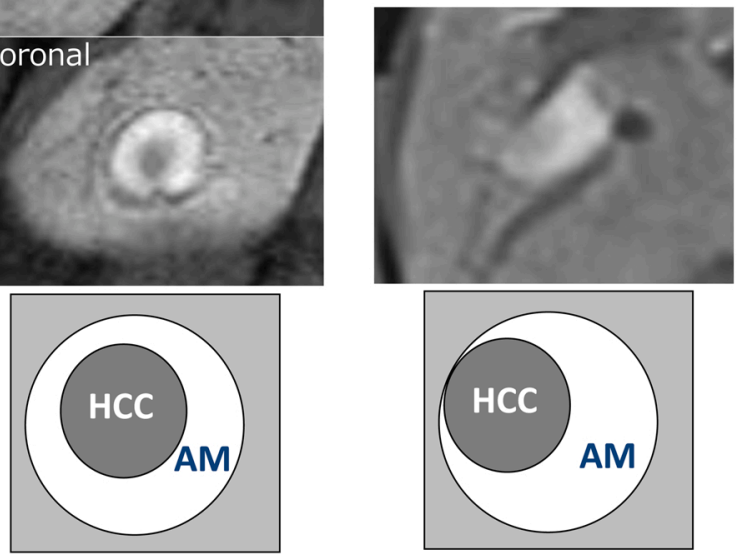

Ablative margin $(+)$

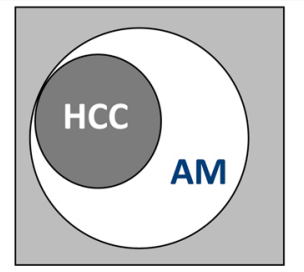

Ablative margin (0)
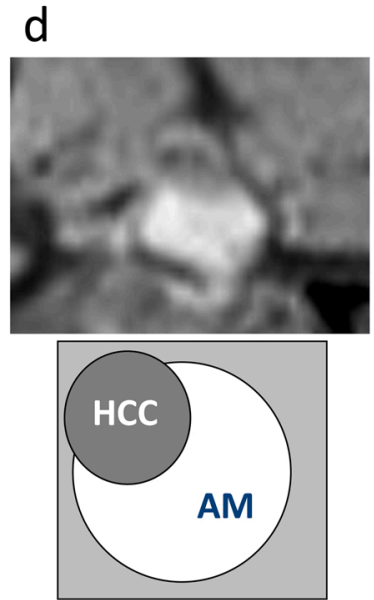

Ablative margin $(-)$

Fig. 3. Evaluation of the therapeutic effect by MRI.

a. A HCC nodule (arrow) was visualized at the hepatobiliary phase in the enhanced MRI with Gd-EOB-DTPA $(0.1 \mathrm{~mL} / \mathrm{kg}$ body weight). Gd-EOB-DTPA $(0.1 \mathrm{~mL} / \mathrm{kg}$ body weight) was injected 10-20 min before ablation. MRI was performed within $7 \mathrm{~h}$ of RFA.

b. The transverse, sagittal and coronal images show a low-intensity area with a continuous high-intensity rim, which was defined as $\mathrm{AM}(+)$.

c. A low-intensity area with a discontinuous high-intensity rim was defined as $\operatorname{AM}(0)$.

d. A low-intensity area that extended beyond the rim with tumor protrusion was defined as $\operatorname{AM}(-) \operatorname{AM}(+)$ and $\operatorname{AM}(0)$ were classified as a sufficient $\operatorname{AM}$ and $\operatorname{AM}(-)$ as an insufficient AM.

AM, ablative margin; Gd-EOB-DTPA, gadolinium ethoxybenzyl diethylenetriamine pentaacetic acid; MRI, magnetic resonance imaging; RFA, radiofrequency ablation.

tumor.

\subsection{Statistical analysis}

All data are expressed as the mean and standard deviation. For comparison between visualized and non-visualized nodules, continuous variables were analyzed using the Student's $t$-test and categorical variables were analyzed using the chi-square test. The Kaplan-Meier method was used to calculate the cumulative rates of local tumor progression, which were compared using the log-rank test. A logistic regression model was used for multivariate analysis of independent factors for predicted $\mathrm{AM}(+)$ on preablation 3D-US. The Cox proportional hazards model was used for multivariate analysis of independent risk factors for local tumor progression after RFA. The data were analyzed using Stat Flex version 6.0 (Artech Co., Ltd, Osaka, Japan). A p-value $<0.05$ was considered statistically significant.

\section{Results}

\subsection{Visualization of HCC nodules on 3D-US before ablation}

We investigated the visualization of HCC nodules on the C-plane of 3D-US when the RFA electrode was inserted into a target nodule under
US A-plane guidance. The C-plane was able to show images for 48 (66 \%) of 73 nodules but not for 25 nodules ( $34 \%$ ). We compared the characteristics of the 48 visualized nodules with those of the 25 nonvisualized nodules (Table 1 ) and the only significant difference was in echogenicity $(p=0.043)$. There was no significant difference in tumor

Table 1

Comparison of the tumor characteristics of visualized nodules vs non-visualized nodules.

\begin{tabular}{|c|c|c|c|}
\hline & $\begin{array}{l}\text { Visualized } \\
\text { nodules }\end{array}$ & $\begin{array}{l}\text { Non-visualized } \\
\text { nodules }\end{array}$ & $\begin{array}{l}\text { Univariate } p \\
\text { value }\end{array}$ \\
\hline Number & 48 & 25 & \\
\hline Tumor size(mm) & $13.2(7.0-30.0)$ & $13.5(8.3-30.0)$ & 0.579 \\
\hline Echogenicity & & & \\
\hline $\begin{array}{l}\text { Hypo/hyper/iso/ } \\
\text { mixed }\end{array}$ & $36 / 9 / 1 / 2$ & $17 / 2 / 5 / 1$ & 0.043 \\
\hline Location & & & \\
\hline $\begin{array}{l}\text { L/A/P } \\
\text { RFA electrode }\end{array}$ & $13 / 20 / 15$ & $8 / 10 / 7$ & 0.902 \\
\hline RTC/cool-tip/Viva & $23 / 13 / 12$ & $12 / 3 / 10$ & 0.231 \\
\hline $\begin{array}{l}\text { Combination of } \\
\text { TACE }\end{array}$ & $9(18.8 \%)$ & $4(16.0 \%)$ & 0.672 \\
\hline
\end{tabular}

L, liver segment 1, 2, 3 and 4 in left lobe; A, liver segment 5 and 8 in anterior area; P, liver segment 6 and 7 in posterior area; RFA, radiofrequency ablation; TACE, transcatheter arterial chemoembolization. 
size or location, type of RFA electrode used, or combined use of transcatheter arterial chemoembolization (TACE).

\subsection{Comparison of AM predicted by preablation $3 D-U S$ and $A M$ measured on postablation CT/MRI}

Forty-eight HCCs were assessed in this study. The patient demographics and the clinical characteristics of the index tumors are shown in Table 2. All nodules were diagnosed as typical HCCs by the hyperenhancement in the arterial phase with washout in the portal phase with enhanced dynamic CT or with the low intensity in the hepatobiliary phase with enhanced dynamic MRI.

All 48 nodules visualized by 3D-US were ablated successfully in a single session. Five nodules were found to have predicted AM(-) and 43 to have predicted $\mathrm{AM}(+)$ (Table 3 ). The $\mathrm{AM}$ measured on postablation CT/MRI was insufficient for 6 nodules and sufficient for 42 nodules. Thirty-eight nodules were evaluated as predicted AM( + ) by 3D-US and as having a sufficient AM by CT/MRI and 1 nodule was evaluated as predicted AM( $(-)$ by 3D-US and as having an insufficient AM by CT/MRI. An agreement was found between 3D-US and CT/MRI in 39 (81 \%) of the 48 nodules. Next, we classified the nodules according to whether AM predicted by 3D-US was $\geq 3 \mathrm{~mm}$ or $<3 \mathrm{~mm}$ (Table 4 ). Nineteen nodules with predicted $\mathrm{AM} \geq 3 \mathrm{~mm}$ by 3D-US were evaluated as having a sufficient AM on CT/MRI and 4 of 27 nodules with predicted $\mathrm{AM}<3 \mathrm{~mm}$ by 3D-US were evaluated as insufficient AM by CT/MRI. Agreement between 3D-US and CT/MRI was found for 23 (47.9\%) of the 48 nodules.

\subsection{Local tumor progression rates according to predicted AM on 3D-US and the AM measured on enhanced CT/MRI}

All 48 nodules that were assessed as having predicted $\mathrm{AM}(+)$ or $\mathrm{AM}$ $(-)$ by 3D-US were followed up after RFA. The mean observation period was $802 \pm 388$ days. Local progression occurred in 5 of the HCCs (Fig. 4). Local tumor progression was detected in $3(7 \%)$ of 43 nodules with predicted $\mathrm{AM}(+)$ and $2(40 \%)$ of the 5 nodules with predicted AM $(-)$. The cumulative local tumor progression rates were significantly lower for the predicted $\mathrm{AM}(+)$ nodules $(7 \%$ at 1 year, $7 \%$ at 2 years, and $7 \%$ at 3 years) than for the predicted $\mathrm{AM}(-)$ nodules ( $40 \%$ at 1 year, 40 $\%$ at 2 years, and $40 \%$ at 3 years; $p=0.03$ ) (Fig. 5). None of the 21 nodules with predicted $\mathrm{AM} \geq 3 \mathrm{~mm}$ showed local progression. However, local progression occurred in $5(18.5 \%)$ of the 27 nodules with predicted $\mathrm{AM}<3 \mathrm{~mm}$. The cumulative local tumor progression rates were significantly lower in the nodules with predicted $\mathrm{AM} \geq 3 \mathrm{~mm}(0 \%$ at 3 years) than in those with predicted $\mathrm{AM}<3 \mathrm{~mm}$ ( $21 \%$ at 1 year, 21 $\%$ at 2 years, and $21 \%$ at 3 years; $p=0.04$ ) (Fig. 6). Local tumor progression was detected in $2(4.7 \%)$ of the 42 nodules with a sufficient AM on postablation CT/MRI and in 3 (50\%) of 6 with an insufficient AM.

Table 2

Clinical characteristics of the 42 patients ( 48 nodules).

\begin{tabular}{lll}
\hline & Nodules & Patients \\
\hline Mean age (range), years & & $75(48-90)$ \\
Male/female & & $27: 15$ \\
Etiology of HCC & 7 & 7 \\
Hepatitis B & 29 & 24 \\
Hepatitis C & 0 & 0 \\
Hepatitis B + C & 8 & 8 \\
Alcohol & 4 & 3 \\
Cryptogenic & & \\
Underlying liver disease & 18 & 16 \\
Chronic hepatitis & & \\
Cirrhosis & 24 & 20 \\
Pugh A & 6 & 6 \\
Pugh B & $10 / 38$ & $9 / 33$ \\
HCC (first-diagnosed/recurrent) & & \\
\hline
\end{tabular}

HCC, hepatocellular carcinoma.
Table 3

Comparison of the assessment of the predictive AM by preablation 3D-US vs the assessment of measured AM by postablation CT/MRI in 48 HCCs.

\begin{tabular}{cllll}
\hline & & \multicolumn{2}{l}{ Preablation 3D-US } & \\
\cline { 3 - 4 } & & $\begin{array}{l}\text { Predictive AM } \\
(+)\end{array}$ & $\begin{array}{l}\text { Predictive AM } \\
(-)\end{array}$ & total \\
\hline \multirow{3}{*}{$\begin{array}{c}\text { Postablation CT/ } \\
\text { MRI }\end{array}$} & $\begin{array}{l}\text { sufficient AM } \\
\text { insufficient }\end{array}$ & 38 & 4 & 42 \\
& AM & 5 & 1 & 6 \\
& total & 43 & 5 & 48 \\
\hline
\end{tabular}

3D-US, three-dimensional ultrasonography; AM, ablative margin; CT, computed tomography; HCC, hepatocellular carcinoma; MRI, magnetic resonance imaging.

Table 4

Comparison of the assessment of the predicted AM (cutoff value: $3 \mathrm{~mm}$ ) by preablation 3D-US vs the assessment of measured AM by postablation CT/MRI in 48 HCCs.

\begin{tabular}{cllll}
\hline & & \multicolumn{2}{l}{ Preablation 3D-US } & \\
\cline { 3 - 4 } & & $\begin{array}{l}\text { Predictive } \\
\mathrm{AM} \geq 3\end{array}$ & $\begin{array}{l}\text { Predictive } \\
\mathrm{AM}<3\end{array}$ & \\
\hline \multirow{3}{*}{$\begin{array}{c}\text { Postablation CT/ } / \\
\text { MRI }\end{array}$} & $\begin{array}{l}\text { sufficient AM } \\
\text { insufficient }\end{array}$ & 19 & 23 & 42 \\
& AM & 21 & 4 & 6 \\
& total & 21 & 27 & 48 \\
\hline
\end{tabular}

3D-US, 3-dimensional ultrasonography; AM, ablative margin; CT, computed tomography; HCC, hepatocellular carcinoma; MRI, magnetic resonance imaging.

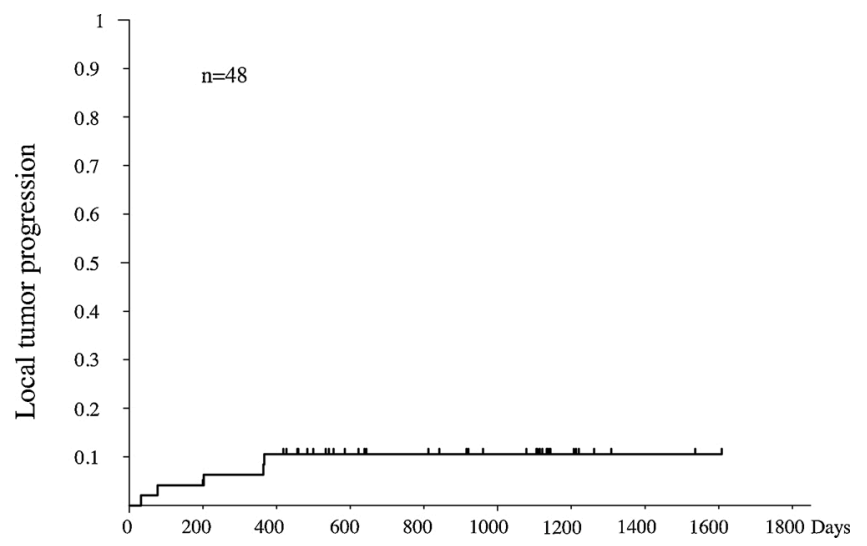

Fig. 4. Cumulative local tumor progression rate for all 48 nodules. Five of the 48 visualized HCC nodules progressed. Local progression was detected for 2 nodules at 3 months after RFA, for 1 nodule at 6 months, and for 2 nodules at $>12$ months. HCC, hepatocellular carcinoma; RFA, radiofrequency ablation.

The cumulative local tumor progression rates were significantly lower for the nodules with a sufficient AM $(4.8 \%$ at 1 year, $4.8 \%$ at 2 years, and $4.8 \%$ at 3 years) than for the nodules with an insufficient AM (50\% at 1 year, $50 \%$ at 2 years, and $50 \%$ at 3 years; $\mathrm{p}=0.00008$ ) (Fig. 7 ).

\section{Discussion}

This study has demonstrated three novel findings. First, $66 \%$ of HCC nodules could be visualized in the C-plane on 3D-US. Second, the predicted AM on preablation 3D-US showed good agreement (in $81 \%$ of cases) with the AM measured on postablation CT/MRI. Third, the cumulative local tumor progression rate was significantly lower for the predicted $\mathrm{AM}(+)$ nodules than for predicted $\mathrm{AM}(-)$ nodules. Furthermore, no nodules with predicted $\mathrm{AM} \geq 3 \mathrm{~mm}$ showed local tumor 


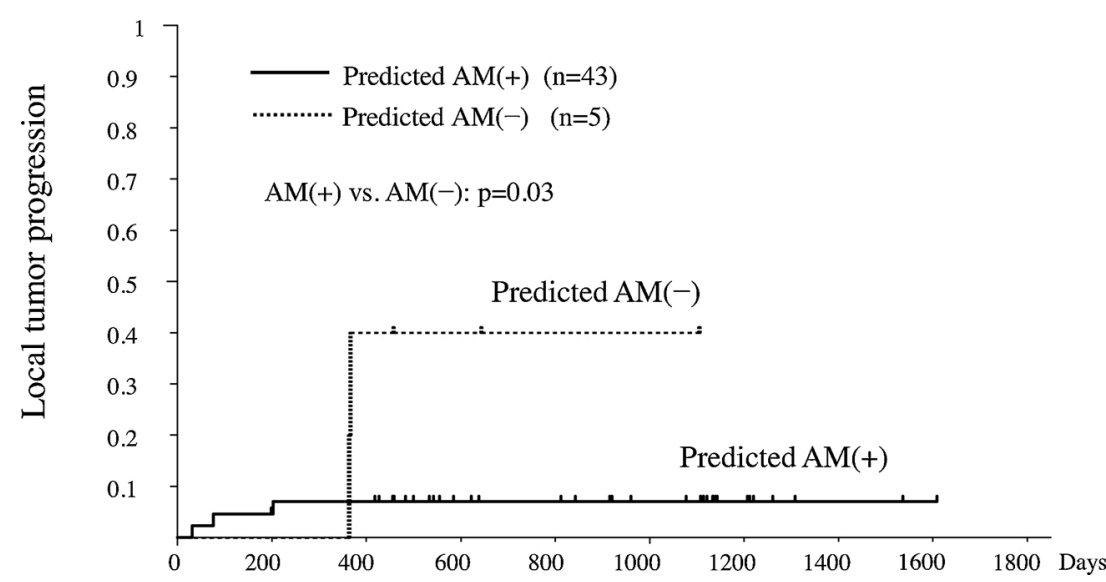

Fig. 5. Cumulative local tumor progression rates for predicted $\mathrm{AM}(+)$ vs predicted $\mathrm{AM}(-)$.

The progression rate was lower for the predicted $\operatorname{AM}(+)$ nodules than for predicted $\operatorname{AM}(-)$ nodules $(\mathrm{p}=0.03)$. AM, ablative margin.

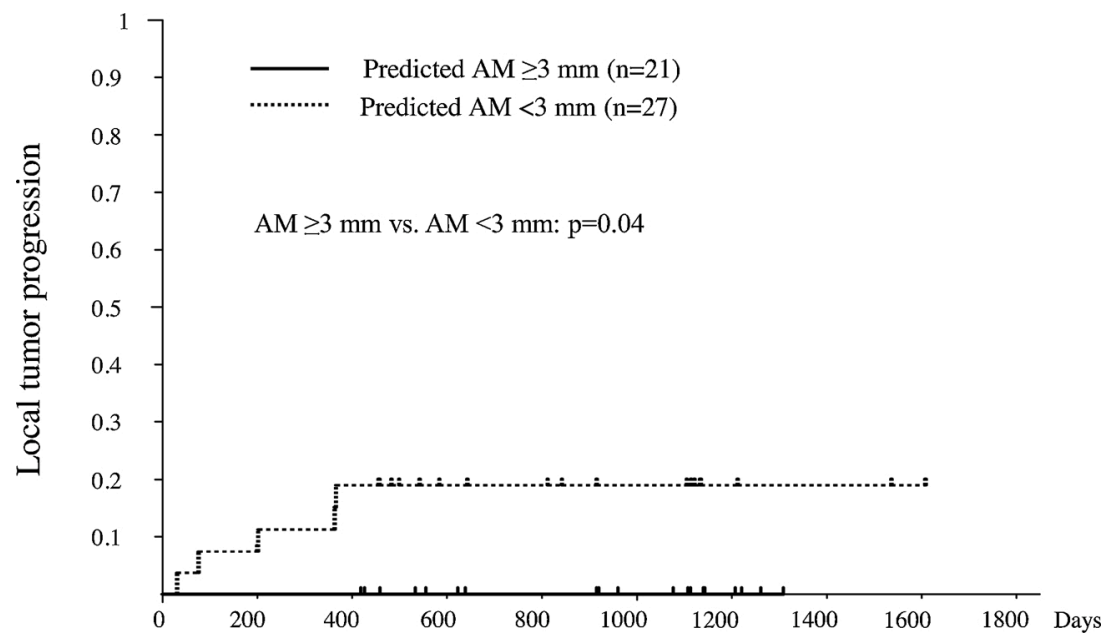

Fig. 6. Cumulative local tumor progression rates for predicted $\mathrm{AM} \geq 3 \mathrm{~mm}$ vs $<3 \mathrm{~mm}$.

The progression rate was lower for nodules with predicted $\mathrm{AM} \geq 3 \mathrm{~mm}$ than for those with predicted $\mathrm{AM}<3 \mathrm{~mm}(\mathrm{p}=0.04)$. AM, ablative margin.

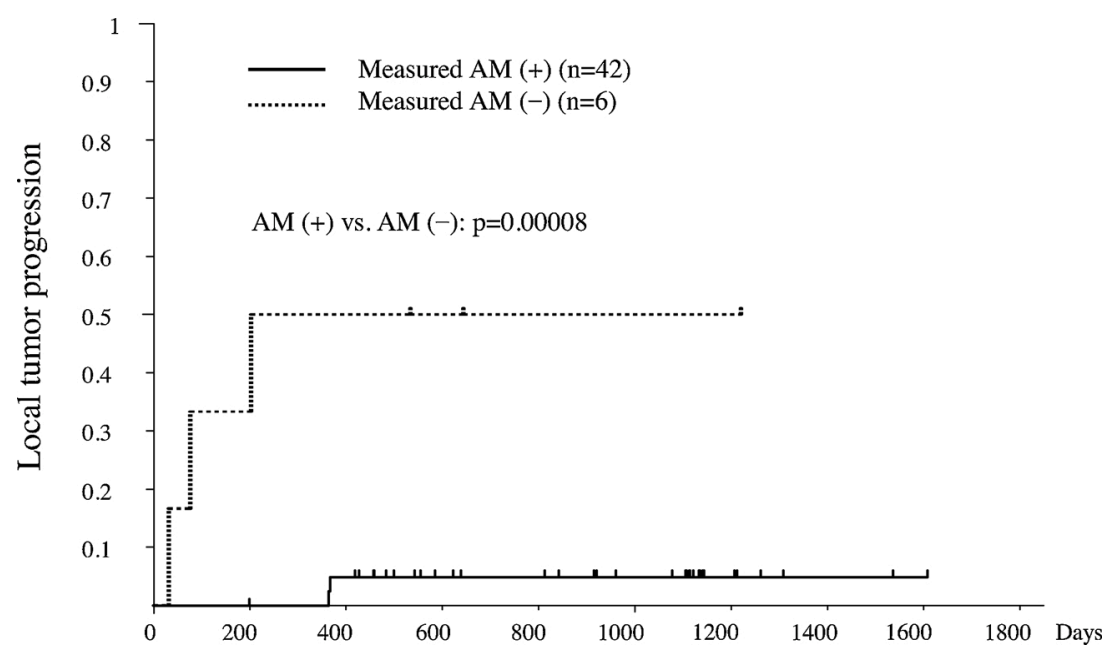

Fig. 7. Cumulative local tumor progression rates for measured $\mathrm{AM}(+)$ vs measured $\mathrm{AM}(-)$.

The progression rate was lower for the measured $\mathrm{AM}(+)$ nodules than for the measured $\mathrm{AM}(-)$ nodules $(\mathrm{p}=0.00008)$. AM, ablative margin.

progression.

The location of the RFA electrode in the tumor is easier to recognize on preablation 3D-US. Therefore, obtaining 3D-US images after RFA electrode insertion would be a good strategy for successful ablation. However, visualization of the tumor border on 3D-US is not always sufficient, especially in the C-plane. Initially, we attempted to visualize 
HCC nodules in the C-plane on 3D-US. The C-plane is the most important plane when assessing the ablative margin. Visualization of the tumor border and RFA electrode in the C-plane predicts the ablative margin possible because the ablation volume achieved by RFA is almost constant. To date, there have been no reports on visualization rates for HCC nodules in C-plane reconstructed from 3D volume data. In the present study, $66 \%$ of HCC nodules were visualized in C-plane, although all nodules were less than $30 \mathrm{~mm}$. There was no significant difference in tumor size or location, type of RFA electrode used, or combined use of TACE between the visualized nodules and non-visualized nodules in Cplane. The only factor affecting visualization of the HCC nodule in Cplane was echogenicity. There were more hyperechoic nodules in the visualized group than in the non-visualized group and more isoechoic nodules in the non-visualized group than in the visualized group. Therefore, hyperechogenicity is advantageous and isoechogenicity is disadvantageous for visualization of HCC nodules on 3D-US.

There are some drawbacks concerning the devices used for 3D-US. The 3D-US probe is thick, and the acoustic shadowing caused by the ribs obscures the US images, meaning that adequate images cannot always be obtained in patients with a narrow intercostal space. Furthermore, a clear image cannot be obtained for deeper HCC nodules present. Further research that includes more cases is needed to solve these problems. Finally, nodules that cannot be visualized on 3D-US need to be assessed by conventional postablation CT/MRI methods. However, in the near future, higher visualization rates can be expected as a result of improvement in the US equipment.

We compared the AM values assessed on preablation 3D-US (predicted AM) with those measured on postablation CT/MRI and the findings were consistent for 39 (89\%) of 48 nodules. The discrepant findings were the result of overestimation of the predicted AM in 5 cases and underestimation in the remaining 4 . The good match rate between the two methods indicates that grading based on predicted AM is clinically feasible. Predicted AM can be assessed at the time of puncture and before ablation. Therefore, even if predicted $\mathrm{AM}(-)$ is found on 3D-US after puncture by the RFA electrode, the puncture can be repeated in a more appropriate position. A previous study [27] showed that 3D-US greatly increased the confidence level of the operator when defining the positional relationship between the electrode and the tumor. Furthermore, 3D-US allows better visualization of the critical tissue structures surrounding the RFA electrode, such as the portal vein, bile duct, diaphragm, gallbladder, colon, and kidney, which might help to avoid injuries of adjacent critical structures by a misplaced RFA electrode.

This study also showed that the local tumor progression rates for predicted $\mathrm{AM}(+)$ nodules were significantly lower than those for predicted $\mathrm{AM}(-)$ nodules. Similarly, the local tumor progression rates for measured $\mathrm{AM}(+)$ nodules were significantly lower than those for measured $\mathrm{AM}(-)$ nodules. However, the local tumor progression rate at 1 year was $9.3 \%$ for predicted $\mathrm{AM}(+)$ nodules and $4.8 \%$ for measured $\mathrm{AM}(+)$ nodules. This finding indicates that assessment of predicted $\mathrm{AM}$ may not be as precise as the measured AM. Therefore, we defined predicted $\mathrm{AM} \geq 3 \mathrm{~mm}$ as the largest predicted $\mathrm{AM}$ for obtaining complete ablation, including distant microsatellite lesions. No local tumor progression was found for nodules with predicted $\mathrm{AM} \geq 3 \mathrm{~mm}$. We conclude that predicted $\mathrm{AM} \geq 3 \mathrm{~mm}$ is better than or equal to measured $\mathrm{AM}(+)$. In previous studies, an $\mathrm{AM}$ of $\geq 3-5 \mathrm{~mm}$ was recommended to control local tumor progression of HCCs measuring up to $30 \mathrm{~mm}$ [11, 15]. In our present study, the AM was measured mainly on postablation MRI with or without Gd-EOB-DTPA enhancement. Our previous study demonstrated that an $\mathrm{AM}(+)$ on MRI was equivalent to an AM of 3-5 mm on dynamic CT [23]. Therefore, predicted $\mathrm{AM} \geq 3 \mathrm{~mm}$ is consistent with an AM of $3 \mathrm{~mm}$ measured by conventional dynamic CT.

A larger $A M(\geq 3 \mathrm{~mm})$ may cause serious complications, such as portal thrombus, bile duct injury, hepatic infarction, and extrahepatic organ injury. As mentioned earlier, 3D-US allows better visualization of the positional relationship between the surrounding critical structures and RFA electrode and safer insertion of the RFA electrode before ablation. New MWA equipment based on internal cooling (Emprint ablation system, Medtronic, Tokyo, Japan) is able to create a predictable ablation zone using a range of power settings and a range of ablation times $[28,29]$. That is, the ablation volume needed to obtain an $\mathrm{AM} \geq 3 \mathrm{~mm}$ is calculated by measurement of the distance between the electrode and the edge of the HCC nodule on 3D-US, and complete ablation with an $\mathrm{AM} \geq 3 \mathrm{~mm}$ can be obtained by energy control using this MWA system.

This study has some limitations. First, the number of cases was relatively small. Therefore, visualization on 3D-US should be confirmed in a larger number of nodules. Second, a 3D-US examination requires advanced technical skills, so all 3D-US examinations in this study were performed by the same investigator. This may have resulted in potential bias. However, if an examiner has some experiences, he can fully use 3DUS. Third, we could not pathologically validate the AM in the ablation zone. Fourth, the focus of this study was investigating local tumor progression rate, so we did not evaluate overall survival rates after RFA according to the predicted AM on 3D-US because many of the nodules were recurrent.

\section{Conclusion}

This study clearly showed that 3D-US is a useful tool for prediction of the $\mathrm{AM}$ before ablation and that predicted $\mathrm{AM}(+)$ or predicted $\mathrm{AM} \geq 3 \mathrm{~mm}$ indicates low or no risk of local tumor progression. Preablation 3D-US is a useful and noninvasive method for assessment of the AM achieved by RFA for HCC.

\section{Funding}

This research did not receive any specific grant from funding agencies in the public, commercial, or not-for-profit sectors.

\section{Transparency document}

The Transparency document associated with this article can be found in the online version.

\section{CRediT authorship contribution statement}

Yukako Matsuki: Writing - original draft, Investigation, Data curation, Formal analysis. Tomomitsu Matono: Conceptualization, Methodology, Formal analysis, Investigation, Data curation, Writing review \& editing, Visualization, Supervision, Project administration. Masahiko Koda: Conceptualization, Methodology, Formal analysis, Investigation, Data curation, Writing - review \& editing, Visualization, Supervision, Project administration. Kenichi Miyoshi: Data curation. Takaaki Sugihara: Data curation. Jun-ichi Okano: Supervision. Hajime Isomoto: Supervision.

\section{References}

[1] Cancer Today, The Global Cancer Observatory, International Agency for Research on Cancer, 2019 (accessed 15 February 2020), http://gco.iarc.fr/today/dat a/factsheets/cancers/11-Liver-fact-sheet.pdf/.

[2] J.K. Heimbach, L.M. Kulik, R.S. Finn, C.B. Sirlin, M.M. Abecassis, L.R. Roberts, A. X. Zhu, M.H. Murad, J.A. Marrero, AASLD guidelines for the treatment of hepatocellular carcinoma, Hepatology 67 (2018) 358-380, https://doi.org/ 10.1002/hep. 29086.

[3] P.R. Galle, A. Forner, J.M. Llovet, V. Mazzaferro, F. Piscaglia, J.L. Raoul, P. Schirmacher, V. Vilgrain, EASL clinical practice guidelines: management of hepatocellular carcinoma, J. Hepatol. 69 (2018) 182-236, https://doi.org/ 10.1016/j.jhep.2018.03.019.

[4] Clinical Practice Guidelines for Hepatocellular Carcinoma, The Japan Society of Hepatology, 2013, 2013 (accessed 15 February 2020, http://www.jsh.or.jp/Engli sh/guidelines_en/Guidelines_for_hepatocellular_carcinoma_2013.

[5] K. Hasegawa, M. Makuuchi, T. Takayama, N. Kokudo, S. Arii, M. Okazaki, K. Okita, M. Omata, M. Kudo, M. Kojiro, Y. Nakanuma, K. Takayasu, M. Monden, Y. Matsuyama, I. Ikai, Surgical resection vs. percutaneous ablation for 
hepatocellular carcinoma: a preliminary report of the Japanese nationwide survey, J. Hepatol. 49 (2008) 589-594, https://doi.org/10.1016/j.jhep.2008.05.018.

[6] R.E. Schwarz, D.D. Smith, Trends in local therapy for hepatocellular carcinoma and survival outcomes in the US population, Am. J. Surg. 195 (2008) 829-836, https:// doi.org/10.1016/j. amjsurg.2007.10.010.

[7] V.W.T. Lam, K.K.C. Ng, K.S.H. Chok, T.T. Cheung, J. Yuen, H. Tung, W.K. Tso, S T. Fan, R.T.P. Poon, Risk factors and prognostic factors of local recurrence after radiofrequency ablation of hepatocellular carcinoma, J. Am. Coll. Surg. 207 (2008) 20-29, https://doi.org/10.1016/j.jamcollsurg.2008.01.020.

[8] F. Xia, E.C.H. Lai, W.Y. Lau, K. Ma, X. Li, P. Bie, C. Qian, High serum hyaluronic acid and HBV viral load are main prognostic factors of local recurrence after complete radiofrequency ablation of hepatitis B-related small hepatocellular carcinoma, Ann. Surg. Oncol. 19 (2012) 1284-1291, https://doi.org/10.1245/ s10434-011-2042-3.

[9] E. Berber, A. Siperstein, Local recurrence after laparoscopic radiofrequency ablation of liver tumors: an analysis of 1032 tumors, Ann. Surg. Oncol. 15 (2008) 2757-2764, https://doi.org/10.1245/s10434-008-0043-7.

[10] K.K. Shiu, H. Rhim, D. Choi, J.L. Won, H.K. Lim, Y.S. Kim, Local tumor progression after radiofrequency ablation of liver tumors: analysis of morphologic pattern and site of recurrence, Am. J. Roentgenol. 190 (2008) 1544-1551, https://doi.org/ 10.2214/AJR.07.2798.

[11] T. Nakazawa, S. Kokubu, A. Shibuya, K. Ono, M. Watanabe, H. Hidaka, T. Tsuchihashi, K. Saigenji, Radiofrequency ablation of hepatocellular carcinoma: correlation between local tumor progression after ablation and ablative margin, Am. J. Roentgenol. 188 (2007) 480-488, https://doi.org/10.2214/AJR.05.2079.

[12] A. Ayav, A. Germain, F. Marchal, I. Tierris, V. Laurent, C. Bazin, Y. Yuan, L. Robert, L. Brunaud, L. Bresler, Radiofrequency ablation of unresectable liver tumors: factors associated with incomplete ablation or local recurrence, Am. J. Surg. 200 (2010) 435-439, https://doi.org/10.1016/j.amjsurg.2009.11.009.

[13] H. Nishikawa, Y. Osaki, E. Iguchi, H. Takeda, F. Matsuda, J. Nakajima, A. Sakamoto, K. Hatamaru, S. Saito, A. Nasu, R. Kita, T. Kimura, Radiofrequency ablation for hepatocellular carcinoma: the relationship between a new grading system for the ablative margin and clinical outcomes, J. Gastroenterol. 48 (2013) 951-965, https://doi.org/10.1007/s00535-012-0690-0.

[14] S. Mulier, Y. Ni, J. Jamart, T. Ruers, G. Marchal, L. Michel, Local recurrence after hepatic radiofrequency coagulation: multivariate meta-analysis and review of contributing factors, Ann. Surg. 242 (2005) 158-171, https://doi.org/10.1097/01. sla.0000171032.99149.fe.

[15] C.H. Liu, C.Y. Yu, O.A. Catalano, P.R. Mueller, Radiological reasoning: imaging differentiation of a solitary hepatic mass, Am. J. Roentgenol. 190 (2008) 57-61, https://doi.org/10.2214/AJR.07.7005.

[16] M. Koda, S. Tokunaga, K. Miyoshi, M. Kishina, Y. Fujise, J. Kato, T. Matono, Y. Murawaki, S. Kakite, E. Yamashita, Ablative margin states by magnetic resonance imaging with ferucarbotran in radiofrequency ablation for hepatocellular carcinoma can predict local tumor progression, J. Gastroenterol. 48 (2013) 1283-1292, https://doi.org/10.1007/s00535-012-0747-0.

[17] T. Okusaka, S. Okada, H. Ueno, M. Ikeda, K. Shimada, J. Yamamoto, T. Kosuge, S. Yamasaki, N. Fukushima, M. Sakamoto, Satellite lesions in patients with small hepatocellular carcinoma with reference to clinicopathologic features, Cancer. 95 (2002) 1931-1937, https://doi.org/10.1002/cncr.10892.

[18] L. Crocetti, C. Della Pina, D. Cioni, R. Lencioni, Peri-intraprocedural imaging: US, CT, and MRI, Abdom. Imaging 36 (2011) 648-660, https://doi.org/10.1007/ s00261-011-9750-9.

[19] K. Shiozawa, M. Watanabe, R. Takayama, M. Takahashi, N. Wakui, K. Iida, Y. Sumino, Evaluation of local recurrence after treatment for hepatocellular carcinoma by contrast-enhanced ultrasonography using sonazoid: comparison with dynamic computed tomography, J. Clin. Ultrasound 38 (2010) 182-189, https:// doi.org/10.1002/jcu.20685.

[20] Y. Makino, Y. Imai, T. Igura, M. Hori, K. Fukuda, Y. Sawai, S. Kogita, H. Ohama, Y. Matsumoto, M. Nakahara, S. Zushi, M. Kurokawa, K. Isotani, M. Takamura, N. Fujita, T. Murakami, Utility of computed tomography fusion imaging for the evaluation of the ablative margin of radiofrequency ablation for hepatocellular carcinoma and the correlation to local tumor progression, Hepatol. Res. 43 (2013) 950-958, https://doi.org/10.1111/hepr.12049.

[21] T. Motoyama, S. Ogasawara, T. Chiba, T. Higashide, H. Yokota, N. Kanogawa, E. Suzuki, Y. Ooka, A. Tawada, R. Irie, S. Ochi, Y. Masuda, T. Uno, O. Yokosuka, Coronal reformatted CT images contribute to the precise evaluation of the radiofrequency ablative margin for hepatocellular carcinoma, Abdom. Imaging 39 (2014) 262-268, https://doi.org/10.1007/s00261-013-0054-0.

[22] H. Okubo, S. Kokubu, M. Komiyama, H. Yamagata, A. Uchiyama, A. Miyazaki, S. Watanabe, Radiofrequency ablation of hepatocellular carcinoma: the feasibility of magnetic resonance imaging with gadolinium ethoxybenzyl diethylene triamine pentaacetic acid for evaluating the ablative margin, Hepatol. Res. 40 (2010) 1034-1041, https://doi.org/10.1111/j.1872-034X.2010.00709.x.

[23] M. Koda, S. Tokunaga, T. Okamoto, M. Hodozuka, K. Miyoshi, M. Kishina, Y. Fujise, J. Kato, T. Matono, T. Sugihara, K. Oyama, K. Hosho, J.I. Okano, Y. Murawaki, S. Kakite, E. Yamashita, Clinical usefulness of the ablative margin assessed by magnetic resonance imaging with Gd-EOB-DTPA for radiofrequency ablation of hepatocellular carcinoma, J. Hepatol. 63 (2015) 1360-1367, https:// doi.org/10.1016/j.jhep.2015.07.023.

[24] E.J. Xu, S.M. Lv, K. Li, Y.L. Long, Q.J. Zeng, Z.Z. Su, R.Q. Zheng, Immediate evaluation and guidance of liver cancer thermal ablation by three-dimensional ultrasound/contrast-enhanced ultrasound fusion imaging, Int. J. Hyperthermia 34 (2018) 870-876, https://doi.org/10.1080/02656736.2017.1373306.

[25] S. Tokunaga, M. Koda, T. Matono, T. Sugihara, T. Nagahara, M. Ueki, Y. Murawaki, S. Kakite, E. Yamashita, Assessment of ablative margin by MRI with ferucarbotran in radiofrequency ablation for liver cancer: comparison with enhanced CT, Br. J. Radiol. 85 (2012) 745-752, https://doi.org/10.1259/bjr/64518148.

[26] M. Koda, S. Tokunaga, K. Miyoshi, M. Kishina, Y. Fujise, J. Kato, T. Matono, K. Okamoto, Y. Murawaki, S. Kakite, Assessment of ablative margin by unenhanced magnetic resonance imaging after radiofrequency ablation for hepatocellular carcinoma, Eur. J. Radiol. 81 (2012) 2730-2736, https://doi.org/10.1016/j. ejrad.2011.11.013.

[27] H.X. Xu, X.Y. Yin, M. De Lu, X.Y. Xie, Z.F. Xu, G.J. Liu, Usefulness of threedimensional sonography in procedures of ablation for liver cancers: initial experience, J. Ultrasound Med. 22 (2003) 1239-1247, https://doi.org/10.7863/ jum.2003.22.11.1239.

[28] M. Alonzo, A. Bos, S. Bennett, H. Ferral, The Emprint ${ }^{\mathrm{TM}}$ Ablation System with ThermosphereTM Technology: One of the Newer Next-Generation Microwave Ablation Technologies, Semin. Intervent. Radiol. 32 (2015) 335-338, https://doi. org/10.1055/s-0035-1564811.

[29] F. De Cobelli, P. Marra, F. Ratti, A. Ambrosi, M. Colombo, A. Damascelli, C. Sallemi, S. Gusmini, M. Salvioni, P. Diana, F. Cipriani, M. Venturini, L. Aldrighetti, A. Del Maschio, Microwave ablation of liver malignancies: comparison of effects and early outcomes of percutaneous and intraoperative approaches with different liver conditions: new advances in interventional oncology: state of the art, Med. Oncol. 34 (2017) 1-11, https://doi.org/10.1007/ s12032-017-0903-8. 